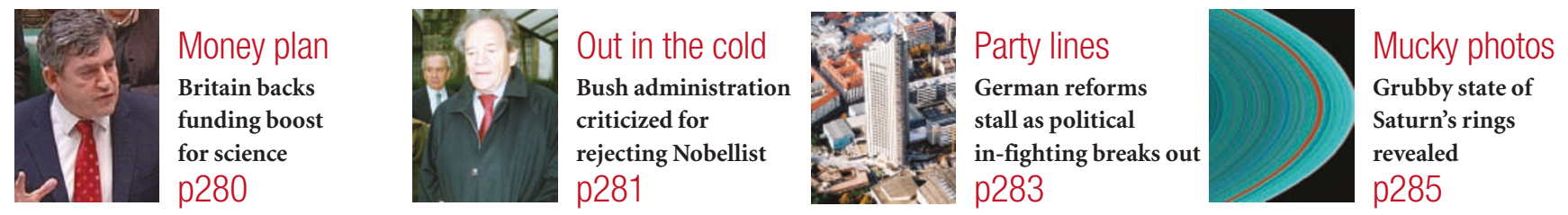

\title{
Aid agencies predict victory for HIV unless cash crisis is solved
}

\section{Erika Check, Bangkok}

For the first time since HIV was identified two decades ago, the global effort to contain its spread is beginning to bear fruit. But this progress could be derailed by lack of funds and disagreements over the best way to prevent transmission, speakers told the $\mathrm{XV}$ International AIDS Conference in Bangkok, Thailand, this week.

Since 2000, global spending on AIDS in developing countries has grown by US $\$ 4.8$ billion to $\$ 6$ billion, according to a report released on 12 July by the Joint United Nations Programme on HIV/AIDS (UNAIDS). And the investment is starting to pay off, leaders at the Bangkok meeting said.

"Finally the political, technical and financial resources are starting to move, and that changes everything," said Peter Piot, executive director of UNAIDS. "Now, we must work even harder to make that money work on a massive scale."

One of the main instruments for the effort, the Global Fund to Fight AIDS, Tuberculosis and Malaria, had barely opened for business when the last international AIDS conference was held in Barcelona in 2002. But Richard Feachem, its director, told the meeting that its efforts have already reached some 2.3 million people. The fund has distributed antiretroviraldrugs to 5,200 HIV-positive patients, and has cured 45,000 people of tuberculosis.

Yet many large donor nations still prefer to invest in their own, bilateral AIDS programmes, and the fund is struggling to meet its income targets. It faces a cash shortfall of $\$ 100$ million this year, and a huge \$2.6-billion shortfall on a projected budget of $\$ 3.5$ billion next year. Overall, UNAIDS says that worldwide spending on AIDS in 2005 will fall $\$ 6$ billion short of the $\$ 12$ billion needed to fight the epidemic effectively.

Donor nations have scrutinized the Global Fund's plans intensely, its officials say, partly because it is the first major aid effort to give money to nations that have written their own action plans, rather than exporting pre-made programmes overseas. Feachem said the fund has proved that this model works, and speakers from developing countries agreed that it meets their needs better than the old model.

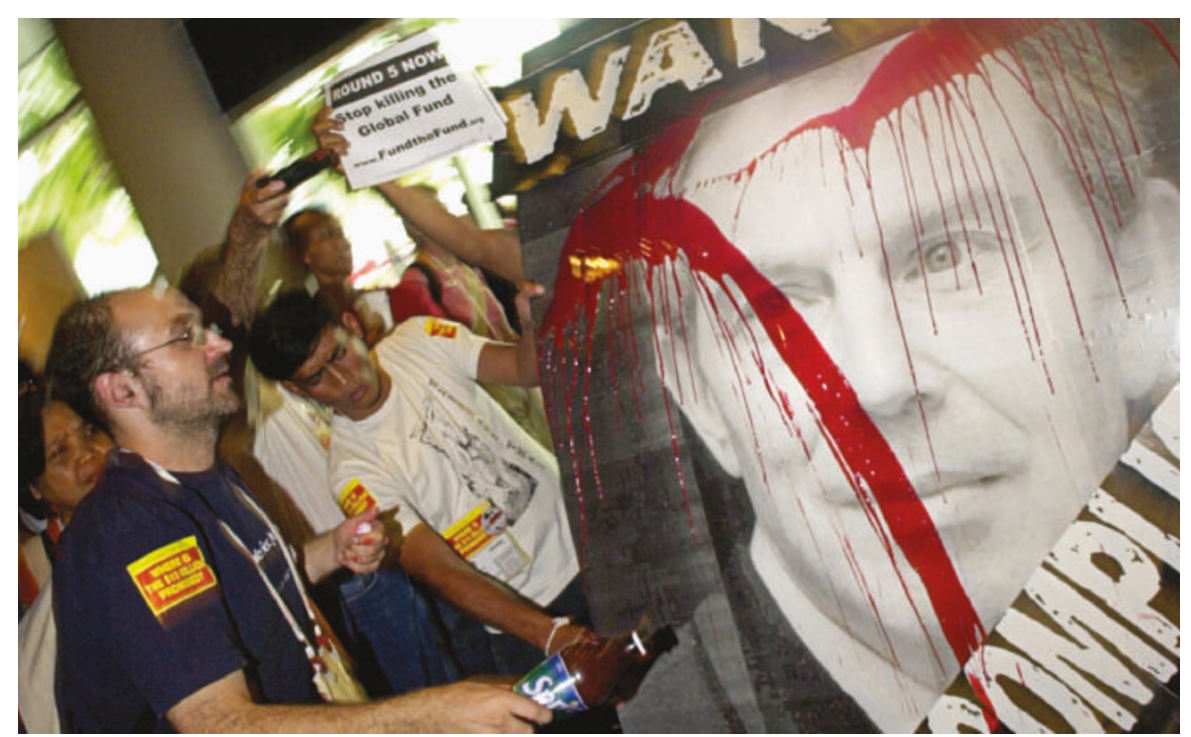

In your face: AIDS activists deface a picture of Tony Blair in a Bangkok protest against the G8 nations.

"Many donors are driven by their national ideologies, rather than by scientifically proven approaches and responses," says Bizwick Mwale, executive director of the National AIDS Commission of Malawi.

As a result, aid recipients say, programmes are often out of tune with local needs. Donors tell local officials what to say, says Serara Mogwe, of the University of Botswana School of Nursing in Gaborone, "and we end up talking to our people in a strange language that they don't understand". In the past, Mogwe adds, the emphasis has been on sex education and condom use. But, she says, the public discussion of either is almost impossible in Botswana, which has the second-highest rate of HIV infection in the world.

\section{Three-point plan}

Now, the United States - the largest donor for AIDS prevention and treatment - is promoting a mantra known as ABC: abstinence, be faithful and use condoms. This approach was widely castigated in Bangkok, where 17,000 scientists, activists and officials have gathered for the AIDS meeting. Activists and some researchers are particularly critical of a congressional stipulation that requires one-third of the money allocated to preven- tion programmes under the US President's Emergency Plan for AIDS Relief to be used for projects in abstinence and monogamy.

"You're not doing what countries want or what people with AIDS want," Gregg Gonsalves of the US activists' group Gay Men's Health Crisis told a US official at a panel on 12 July. "You're trying to please George Bush's conservative base."

But Randall Tobias, global AIDS coordinator at the US Department of State, said Bush has not turned his back on condoms. "Condom use is appropriate when people decide to engage in high-risk behaviour," said Tobias. "Condoms are an important part of our overall strategy."

Bush was not the only world leader drawing fire at the conference. In a demonstration on 12 July, protesters branded leaders of all the G8 club of rich nations 'AIDS accomplices' for not giving enough to the Global Fund and other AIDS efforts.

Feachem, meanwhile, warns that the fund will have to postpone its next round of grants until 2007, unless it gets more assurances of support soon. "The consequences will be catastrophic," he says. "We will not win the fight against AIDS."

www.aids2004.org 